Published in final edited form as:

J Am Chem Soc. 2005 April 27; 127(16): 5766-5767.

\title{
Hydroboration with Pyridine Borane at Room Temperature
}

\author{
Julia M. Clay and Edwin Vedejs \\ Department of Chemistry, University of Michigan, Ann Arbor, Michigan 48109 \\ Department of Chemistry, University of Michigan, Ann Arbor, Michigan 48109E-mail: \\ edved@umich.edu
}

Hydroboration has been an essential reaction in synthetic organic chemistry since Brown's discovery that borane etherates are reactive at room temperature. ${ }^{1,2}$ Diverse hydroborating agents including THF borane, dimethyl sulfide borane, 9-BBN, and thexylborane are readily available and offer many options for selective hydroboration. ${ }^{1}$ However, each has limitations as well as advantages and all are air-sensitive. The far more stable pyridine borane $\left(\mathrm{py} \cdot \mathrm{BH}_{3}\right)$ has also been considered as a hydroborating agent, $3 \mathrm{a}, \mathrm{b}$ but heating to $75-100{ }^{\circ} \mathrm{C}$ is required for dissociation to free borane, a prerequisite for $\pi$-complexation of the olefin and eventual hydroboration. Hindered amine boranes dissociate more readily and react at lower temperatures, but they are air-sensitive. ${ }^{3 \mathrm{c}}$ The remaining challenge is to obtain high reactivity without compromising reagent stability and practicality.

We have explored the possibility of activating Py $\mathrm{BH} 3$ by replacing one of the hydrides with a good leaving group (Scheme 1; $\mathrm{Py} \cdot \mathrm{BH}_{2} \mathrm{X}(1)$ with $\mathrm{X}$ ) I, $\mathrm{Br}$, OTf, NTf2). If this approach is used, the strength of the $\mathrm{B}-\mathrm{N}$ bond would no longer be problematic, provided that departure of the new leaving group $\mathrm{X}$ leads to hydroboration. This might occur by some process equivalent to SN2-like displacement of X to form the olefin $\pi$-complex 2 (path A) or an SN1-like heterolysis via 5 (path B), followed by 4-center addition of $\mathrm{B}-\mathrm{H}(\mathbf{3})$ to give 4 . A third possibility is dissociation of $\mathbf{1}$ to $\mathrm{BH}_{2} \mathrm{X}(6$, path $\mathrm{C})$, conventional hydroboration, and complexation with pyridine to afford 4. Prior studies show that intramolecular hydroborations using activated, unsaturated amine and phosphine boranes are consistent with internal versions of paths A or B. ${ }^{4}$ We now report that a similar hydroboration pathway is also viable as an intermolecular process.

Several amine boranes and activation methods were compared to see if intermolecular hydroboration according to Scheme 1 is possible. The best results were achieved when commercially available pyridine borane (Py.BH3) was activated with $50 \mathrm{~mol} \%$ of $\mathrm{I} 2 \mathrm{in}$ dichloromethane to generate $\mathrm{Py} \cdot \mathrm{BH}_{2} \mathrm{I}\left(1\right.$; rapid hydrogen evolution). ${ }^{5}$ Addition of $\beta$ methylstyrene followed by oxidative workup gave alcohol products ( $92 \% ; 15: 1$ ratio, $7 / 8$; entry 1, Table 1). This improved selectivity, compared to the 5:1 ratio using BH3.THF, ${ }^{6}$ suggests that activation produces a unique hydroborating agent and does not simply release $\mathrm{BH} 3$. Activation of Py·BH3 with bromine gave higher selectivity, but a much slower reaction (entry 2), while TfOH and HNTf2 (entries 3 and 4) induced faster but less selective hydroborations.

Next we compared the reagent 1 (X) I) with Lut $\cdot \mathrm{BH}_{2} \mathrm{I}$ (Table 1 , entry 5 ; from lutidene borane $+\mathrm{I} 2$ ) and the known $\mathrm{Me}_{2} \mathrm{~S} \cdot \mathrm{BH}_{2} \mathrm{I}$ (entry 6). ${ }^{7}$ Different hydroboration regioselectivity was found in each case, and unique ${ }^{11} \mathrm{~B}$ NMR signals were observed prior to the addition of alkene (Py-BH ${ }_{2} \mathrm{I}, \delta-28.5 \mathrm{ppm}$; Lut $\cdot \mathrm{BH}_{2} \mathrm{I}, \delta-34.5 \mathrm{ppm} ; \mathrm{Me}_{2} \mathrm{~S} \cdot \mathrm{BH}_{2} \mathrm{I}, \delta-20.5 \mathrm{ppm}$ ). The NMR data do not exclude the presence of $\mathrm{BH}_{2} \mathrm{I}$ in equilibrium with $\mathrm{L} \cdot \mathrm{BH}_{2} \mathrm{I}$ in one or more cases, but the

Supporting Information Available: Experimental procedures and characterization data (PDF). This material is available free of charge via the Internet at http://pubs.acs.org. 
regioselectivity results (entries 1, 5, and 6) prove that dissociation (as in path C) cannot be the only reaction pathway.

The hydroboration of 1-Ph-1-propyne (9) with BH3.THF is reported to give a 3:1 ratio of 10/11, while $\mathrm{sia}_{2} \mathrm{BH}$, thexylBH $\mathrm{B}_{2}$, catecholborane, and $\mathrm{Br}_{2} \mathrm{BH} \cdot \mathrm{SMe}_{2}$ afford mostly $11 .^{8} \mathrm{In}$ contrast, $\mathrm{Py} \cdot \mathrm{BH}_{2} \mathrm{I}$ produces a striking 15:1 selectivity favoring $\mathbf{1 0}$ (Table 2, entry 1 ), an effect that is amplified for $\mathrm{p}-\mathrm{CF}_{3} \mathrm{Ph}$-1-propyne and reversed for the $\mathrm{p}-\mathrm{MeOPh}$ analogue (entries 2

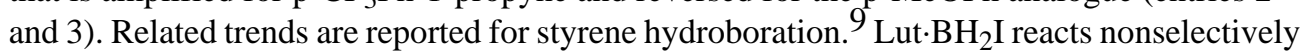
(entry 4), but $\mathrm{Me}_{2} \mathrm{~S} \cdot \mathrm{BH}_{2} \mathrm{I}$ gives $\mathbf{1 0}$ with only traces of $\mathbf{1 1}$ (entry 5). Other alkynes (entries 8 and 9) are hydroborated with low regioselectivity, similar to the results with BH3.THF. ${ }^{8}$

The simplest interpretation of the pyridine and lutidine borane results (Tables 1,2) is that the ligand (L ) Py or Lut) remains attached to boron in the product-determining step for each reaction(Table 1, entries 1 and 5; Table 2, entries 1 and 4). However, the data require only that the $\mathrm{Py} \cdot \mathrm{BH}_{2} \mathrm{I}$ reagent follows a pathway different from path $\mathrm{C}$ (Scheme 1), assuming that the reaction of $\mathrm{Me}_{2} \mathrm{~S} \cdot \mathrm{BH}_{2} \mathrm{I}$ involves dissociation to free $\mathrm{BH}_{2} \mathrm{I}$.

Rate-determining dissociation of 1 (X ) I) to 5 (path B) is ruled out because the rate of methylstyrene hydroboration with $\mathrm{Py} \cdot \mathrm{BH}_{2} \mathrm{I}$ increases with alkene concentration (qualitatively, first order in alkene). The strong counterion dependence for hydroboration regiochemistry (Table 1) also argues against formal dissociation in an SN1-like mechanism, but neither the rate nor the regiochemistry data can rule out pathways where the conversion from $\mathbf{5}$ to $\mathbf{3}$ is ratelimiting if species analogous to tight ion pairs are involved. Path A (Scheme 1) is the simplest rationale that is consistent with facile hydroboration from $\mathrm{Py} \cdot \mathrm{BH}_{2} \mathrm{I}$ at room temperature. By way of analogy, Ryschkewitsch et al. have reported that $\mathrm{Py} \cdot \mathrm{BH}_{2} \mathrm{I}$ reacts readily with nitrogen nucleophiles, resulting in iodide displacement in an SN2-like process. ${ }^{5 b}$ Of course, the alkene is a much weaker nucleophile, and thus it would be premature to conclude that it can be sufficiently reactive to trigger the simplest version of path A. Furthermore, tight ion pair versions of path B cannot be ruled out, and other mechanistic variants remain to be evaluated.

Good functional group compatibility was observed with the $\mathrm{Py} \cdot \mathrm{BH}_{2} \mathrm{I}$ reagent (Table 3). Hydroboration of $\mathbf{1 2}$ followed by oxidative workup gave $>95 \%$ primary alcohols $\mathbf{1 3}$ (NMR assay). Complete conversion of ester, amide, and amine substrates 12d-g required 2 equiv of $\mathrm{Py} \cdot \mathrm{BH}_{2} \mathrm{I}$, but no reduction of these functional groups was observed within $2 \mathrm{~h}$ at room temperature. On the other hand, reduction of ketones and carboxylic acids $(12, \mathrm{R}=\mathrm{C}(\mathrm{O}) \mathrm{Me}$ or $\mathrm{CO}^{2} \mathrm{H}$ ) was fast compared to hydroboration of the alkene.

Monoalkyl boronic acid derivatives cannot be generated directly from unhindered alkenes using $\mathrm{BH} 3$.THF because the initially formed monoalkylborane is more reactive in hydroboration than is the parent $\mathrm{BH} 3 .{ }^{10}$ However, the $\mathrm{Py} \cdot \mathrm{BH}_{2} \mathrm{I}$ method forms the 1:1 adducts considerably faster than 2:1 adducts, as might be expected according to path A (Scheme 1). Thus, hydroboration of 1-dodecene 12a was monitored after quenching in $\mathrm{MeOH}$ using positive ion detection ESMS. Strong signals for the 1:1 adducts $\mathbf{1 4}$ (Z) MeO, Py) were observed, together with a weak signal for the 2:1 adduct 15 (Chart 1). Subsequent treatment with $\mathrm{KHF}_{2}{ }^{11}$ allowed assay in the negative ion detection mode. A strong signal for $\mathbf{1 6}$ was observed, but 17 was not detected after precipitation from acetonitrile. Preparative experiments were performed from alkenes $\mathbf{1 8}$ to afford the corresponding potassium alkyltrifluoroborates 19 in 59-84\% yield (Table 4). In all cases, ESMS with negative ion detection revealed the presence of 1:1 adducts, but not 2:1 adducts. On the other hand, use of excess alkene allowed the ESMS detection of a substantial signal for 17.

Molander has shown that alkyltrifluoroboratesalts are attractive reagents for Suzuki coupling applications, ${ }^{12}$ but preparation of these salts required the use of catecholborane or $\mathrm{BBr}_{2} \mathrm{H} \cdot \mathrm{SMe}_{2}$. The $\mathrm{Py} \cdot \mathrm{BH}_{2} \mathrm{I}$ hydroboration is a simple alternative that cleanly affords the 1:1 
adducts $\mathbf{1 9}$ and provides a high-yielding and convenient route to useful organoborane substrates.

In conclusion, we have presented evidence for an unusual hydroboration mechanism involving leaving group displacement from activated pyridine boranes $\mathbf{1}$. Hydroboration with $\mathrm{Py} \cdot \mathrm{BH}_{2} \mathrm{Iis}$ easily controlled to give the monoadducts and does not require handling sensitive trivalent boranes.

\section{Supplementary Material}

Refer to Web version on PubMed Central for supplementary material.

\section{Acknowledgements}

This work was supported by NIH (CA17918; GM067146).

\section{References}

(1). Brown HC, Subba Rao BC. J. Am. Chem. Soc 1959;81:6423.

(2). Matteson, DS. Stereodirected Synthesis with Organoboranes. Springer-Verlag; New York: 1995. Chapter 2

(3). (a) Hawthorne MF. J. Org. Chem 1958;23:1788. (b) Brown HC, Murray KJ, Murray LJ, Snover JA, Zweifel G. J. Am. Chem. Soc 1960;82:4233. (c) Brown HC, Kanth JVB, Dalvi PV, Zaidlewicz M. J. Org. Chem 2000;65:4655. [PubMed: 10959871] and references therein

(4). Scheideman M, Shapland P, Vedejs E. J. Am. Chem. Soc 2003;125:10502. [PubMed: 12940716]

(5). (a) Ryschkewitsch GE. J. Am. Chem. Soc 1966;88:3145. (b) Ryschkewitsch GE, Garrett JM. J. Am. Chem. Soc 1968;90:7234.

(6). Brown HC, Zweifel G. J. Am. Chem. Soc 1960;82:4708.

(7). Cha JS, Min SJ, Kim JM, Kwon OO, Jeoung MK. Org. Prep. Proced. Int 1993;25:466.

(8). Brown HC, Scouten CG, Liotta R. J. Am. Chem. Soc 1979;101:96.

(9). Brown HC, Sharp RL. J. Am. Chem. Soc 1966;88:5851.

(10). Brown HC, Tsukamoto A, Bigley DB. J. Am. Chem. Soc 1960;82:4703.

(11). Vedejs E, Chapman RW, Fields SC, Lin S, Schrimpf MR. J. Org. Chem 1995;60:3020.

(12). (a) Molander GA, Rivero M. Org. Lett 2001;3:393. [PubMed: 11428022] (b) Molander GA, Yun C-S, Ribagorda M, Biolatto BJ. Org. Chem 2003;68:5534. 


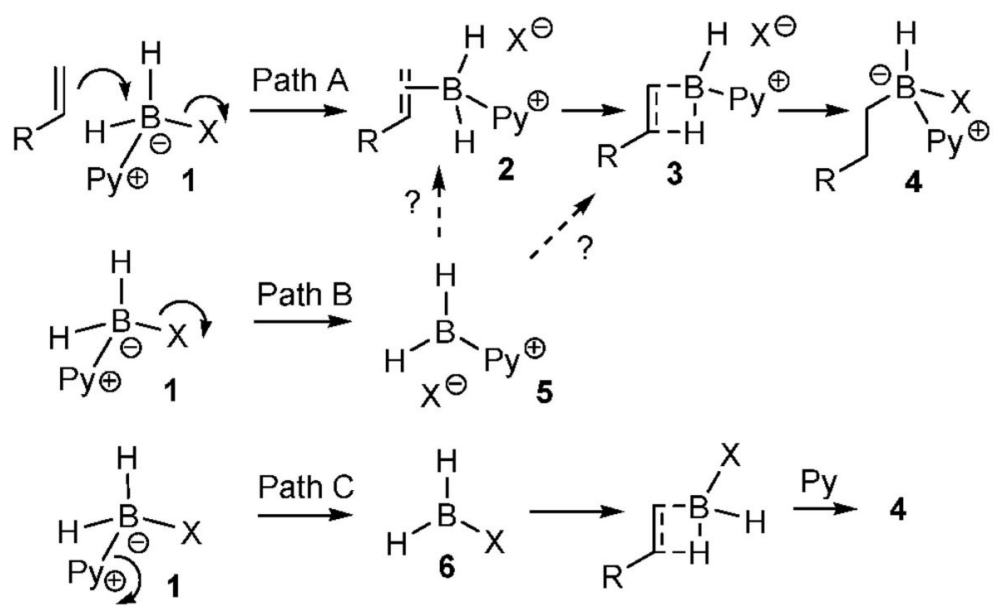

Scheme 1. 


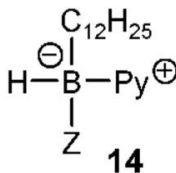

major

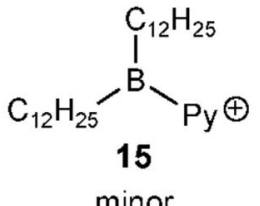

minor

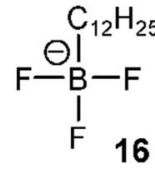

dominant
$\mathrm{F} \stackrel{\stackrel{\ominus}{\mathrm{C}} \stackrel{\mathrm{I}}{\mathrm{B}}_{\mathrm{F}}-\mathrm{C}_{12} \mathrm{H}_{25} \mathrm{H}_{25}}{\mathbf{F}}$

not observed

Chart 1. 
Table 1.

Hydroboration of $\beta$-methylstyrene with $\mathrm{L} \cdot \mathrm{BH}_{2} \mathrm{X}$

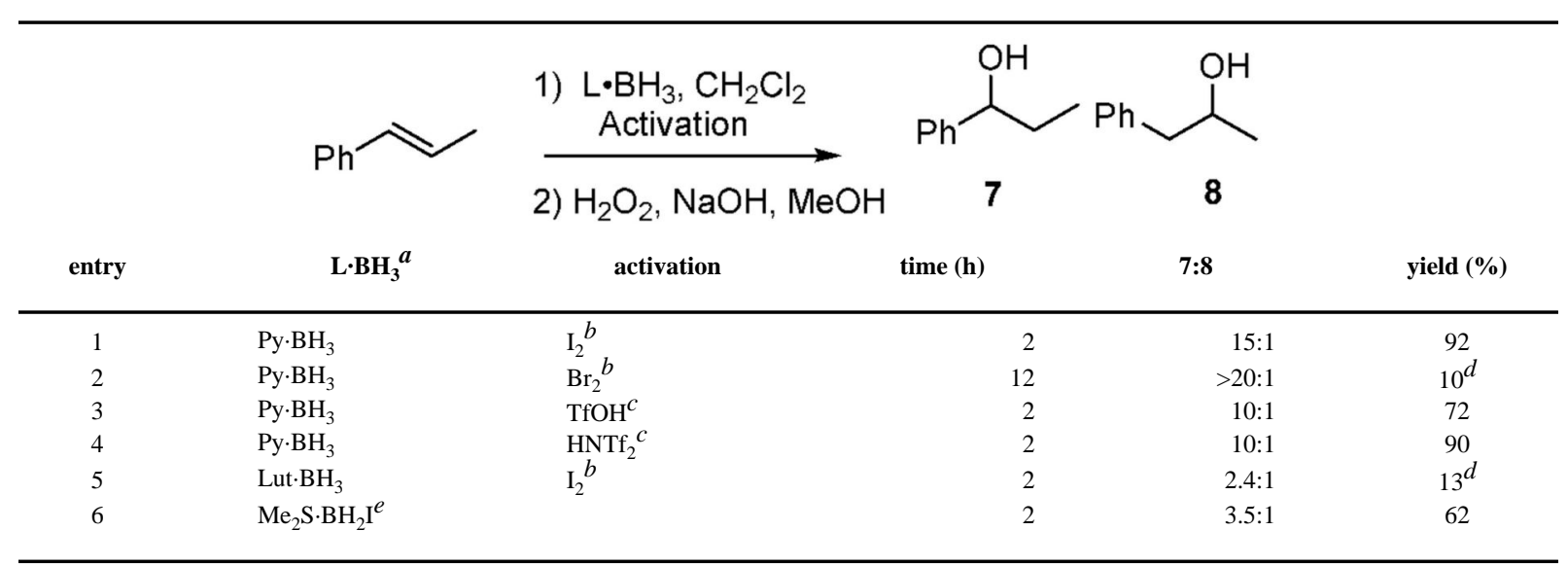

\footnotetext{
$a_{1: 1 \text { ratio, } \mathrm{L} \cdot \mathrm{BH}_{3} / \text { alkene, room temperature. }}$

$b_{50 \mathrm{~mol} \% \text {. }}$

${ }^{c} 100 \mathrm{~mol} \%$.

$d_{\text {Reaction quenched prior to completion. }}$

$e_{\text {Preformed (ref 7). }}$
} 
Alkyne Hydroboration

\section{Table 2.}

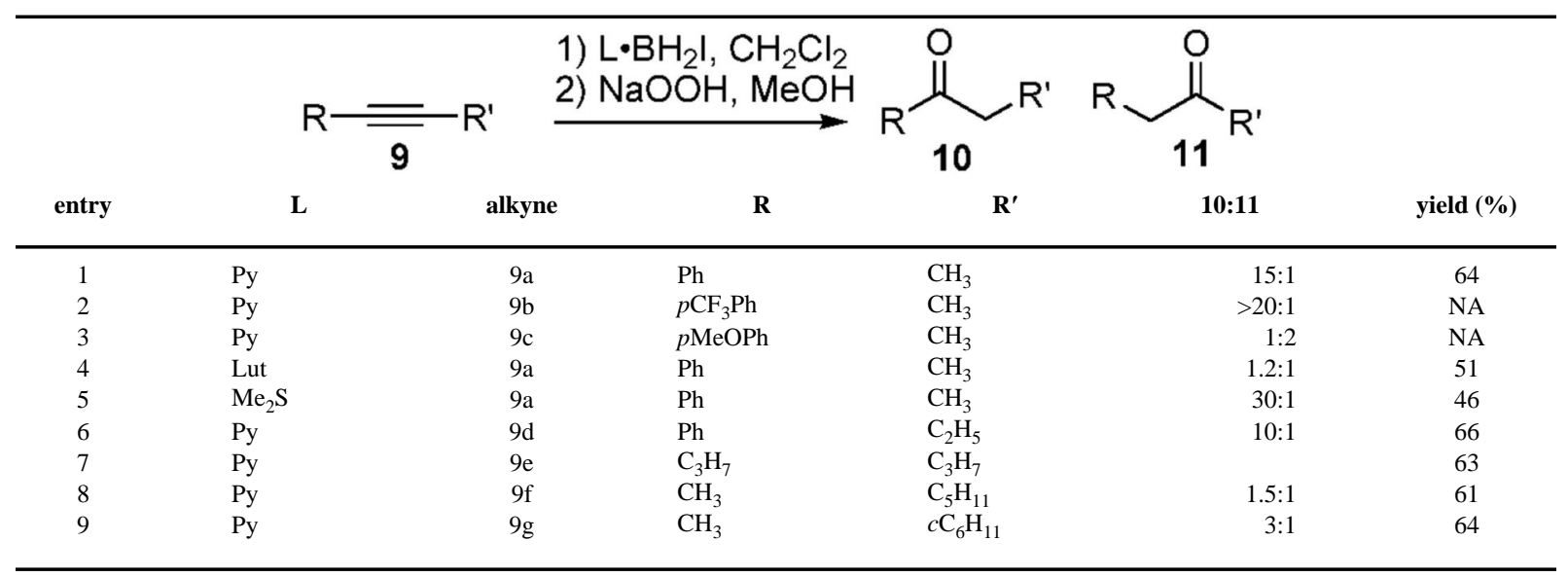


Functional Group Compatibility

Table 3.

\begin{tabular}{|c|c|c|c|c|}
\hline \multirow[b]{2}{*}{ entry } & & 1) $\frac{\mathrm{Py} \cdot \mathrm{BH}_{3}, \mathrm{I}_{2}, \mathrm{CH}_{2} \mathrm{Cl}_{2}}{\text { 2) } \mathrm{H}_{2} \mathrm{O}_{2}, \mathrm{NaOH}, \mathrm{MeOH}}$ & \multirow[t]{2}{*}{$\mathrm{R}\left(\mathrm{CH}_{2}\right)_{4}$} & \multirow[b]{2}{*}{ yield $(\%$} \\
\hline & alkene & $\mathbf{F}$ & & \\
\hline 1 & $12 \mathrm{a}$ & $\mathrm{n}-\mathrm{C}_{6} \mathrm{H}_{13}$ & 98 & \\
\hline 2 & $12 \mathrm{~b}$ & $\mathrm{OBn}$ & 83 & \\
\hline 3 & $12 \mathrm{c}$ & OTBS & 83 & \\
\hline 4 & $12 \mathrm{~d}$ & $\mathrm{OBz}$ & $84,{ }^{a b}$ & \\
\hline 5 & $12 \mathrm{e}$ & $\mathrm{NBn}_{2}$ & $74^{a}$ & \\
\hline 6 & $12 \mathrm{f}$ & NHBn & $80^{a}$ & \\
\hline 7 & $12 \mathrm{~g}$ & $\mathrm{NHBz}$ & $89,{ }^{a b}$ & \\
\hline
\end{tabular}

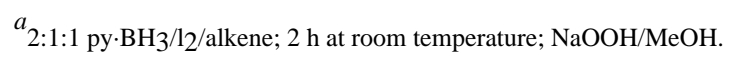

${ }^{b}$ Oxidative workup: $\mathrm{NaBO}_{3} \cdot \mathrm{H}_{2} \mathrm{O}, \mathrm{THF} / \mathrm{H}_{2} \mathrm{O}$.
} 
Table 4.

Preparation of Potassium Alkyltrifluoroborates 19

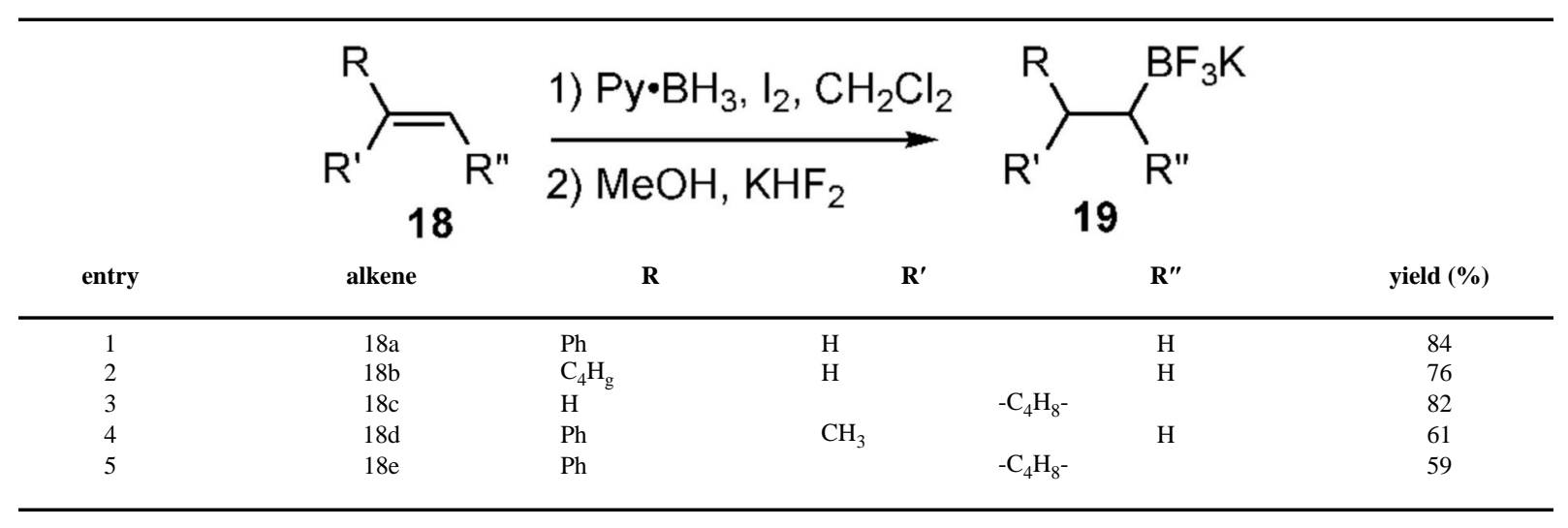

